\title{
Spatiotemporal Distribution and Environmental Drivers of Barley yellow dwarf virus and Vector Abundance in Kansas
}

\author{
L. S. Enders, T. J. Hefley, J. J. Girvin, R. J. Whitworth, and C. M. Smith ${ }^{\dagger}$
}

First author: Department of Entomology, Purdue University, West Lafayette, IN; first, third, fourth, and fifth authors: Department of Entomology, Kansas State University, Manhattan; second author: Department of Statistics, Kansas State University, Manhattan; and third author: USDAAPHIS-PPQ, Federal Way, WA.

Accepted for publication 8 May 2018.

\begin{abstract}
Several aphid species transmit barley yellow dwarf, a globally destructive disease caused by viruses that infect cereal grain crops. Data from $>400$ samples collected across Kansas wheat fields in 2014 and 2015 were used to develop spatiotemporal models predicting the extent to which landcover, temperature and precipitation affect spring aphid vector abundance and presence of individuals carrying Barley yellow dwarf virus (BYDV). The distribution of Rhopalosiphum padi abundance was not correlated with climate or landcover, but Sitobion avenae abundance was positively correlated with fall temperature and negatively correlated to spring temperature and precipitation. The abundance of Schizaphis graminum was negatively correlated with fall precipitation and winter

temperature. The incidence of viruliferous (+BYDV) $R$. padi was positively correlated with fall precipitation but negatively correlated with winter precipitation. In contrast, the probability of +BYDV S. avenae was unaffected by precipitation but was positively correlated with fall temperatures and distance to forest or shrubland. R. padi and S. avenae were more prevalent at eastern sample sites where ground cover is more grassland than cropland, suggesting that grassland may provide oversummering sites for vectors and pose a risk as potential BYDV reservoirs. Nevertheless, land cover patterns were not strongly associated with differences in abundance or the probability that viruliferous aphids were present.
\end{abstract}

The majority of plant viruses rely on intimate relationships with insect vectors for effective transmission and continued survival (Roossinck 2015; Whitfield et al. 2015). Among insect vectors, aphids transmit a staggering $30 \%$ of known viruses (Brault et al. 2010; Nault 1997) through a variety of modes that range from nonpersistent transmission to a circulative-propagative manner (Bragard et al. 2013). In addition, over 200 aphid vector species have been identified globally (Nault 1997; Ng and Perry 2004). Aphids are therefore widely recognized as important viral vectors within cultivated crops and natural ecosystems (Ingwell and Bosque-Pérez 2015; Roossinck 2015). However, there are considerable gaps in our knowledge of the transmission processes governing aphid-vectored diseases in many agroecosystems. In particular, a better understanding of environmental variables that influence vector-virus dynamics could improve predictions and forecasts of disease outbreak and development of control measures.

Barley yellow dwarf (BYD) is a globally destructive disease caused by a group of aphid-vectored viruses belonging to the family Luteoviridae, including Barley yellow dwarf virus (BYDV) and Cereal yellow dwarf virus (CYDV). BYD viruses are considered host generalists, infecting at least 150 grasses in the family Poaceae (grass), including many winter cereals (D'Arcy and Burnett 1995). BYD poses a threat to cultivated crop production worldwide by causing stunting, leaf discoloration and grain shriveling, that can lead to significant yield losses (Miller and Rasochová 1997; Shah

\section{${ }^{\dagger}$ Corresponding author: C. M. Smith; E-mail: cmsmith@ksu.edu}

Funding: Financial support for the research presented in this manuscript was provided by the Kansas Wheat Commission.

*The $\boldsymbol{e}$-Xtra logo stands for "electronic extra" and indicates that three supplementary figures and one supplementary appendix are published online.

(C) 2018 The American Phytopathological Society et al. 2012; Thackray et al. 2009). A suite of at least 25 aphid species transmit BYD Luteoviruses (Miller and Rasochová 1997), with the predominant North American vectors being Rhopalosiphum padi, Rhopalosiphum maidis, Sitobion avenae, Metopolophium dirhodum, and Schizaphis graminum (Gray et al. 1998; Hesler et al. 2005; Power et al. 2011). Transmission efficiency among vectors varies between BYDV strains and in some cases efficiency is highly vector specific (Lucio-Zavaleta et al. 2001; Papura et al. 2002; Power et al. 2011).

Elucidating the molecular underpinnings of aphid-Luteovirus interactions has received considerable attention (Ali et al. 2014; Gray and Gildow 2003), but it is less clear what environmental variables influence BYDV transmission dynamics. Previous studies indicate warmer temperatures facilitate the spread and persistence of BYDV in agroecosystems (Blackmer and Bishop 1991; Habekuss et al. 2009; Lowles et al. 1996; Parry et al. 2012). Autumn aphid infestations are also generally viewed as the primary determinant of virus infection and subsequent yield loss (Chapin et al. 2001; Fabre et al. 2003; Gray et al. 1998; Habekuss et al. 2009; Hesler et al. 2005). However, estimates of BYDV incidence and vector abundance in autumn-sown cereals can vary considerably between years and fields (Fabre et al. 2005; Hesler et al. 2005; Jarošová et al. 2013; Thies et al. 2005). As a result, it has been suggested that patterns of disease outbreak and vector distribution cannot be predicted from region to region (Burnett 1991; Chapin et al. 2001; Kendall and Chinn 1990). Effective BYDV management therefore requires knowledge of the environmental and landscape variables that shape disease distribution and vector biology at a local scale.

In the U.S. Great Plains, BYD is one of the most serious insectvectored diseases affecting cereal crops (Burrows et al. 2009; Hesler et al. 2005; Rotenberg et al. 2016). However, we currently lack an understanding of key ecological variables driving aphidBYDV dynamics that could aide in the development of predictive models for disease risk and yield reduction. In particular, it is unclear whether differences in land usage and proximity to native 
grasses that may act as virus reservoirs can contribute significantly to patterns of BYD outbreak in a particular area. The current study aimed to (i) measure spring aphid distribution and BYDV incidence in Kansas wheat fields over 2 years and (ii) develop spatiotemporal models to predict vector abundance and virus occurrence. We measured the occurrence of viruliferous aphids (+BYDV-PAV), a common North American strain that is vectored by several aphid species, including $R$. padi, S. avenae, and $S$. graminum (Ali et al. 2014; Gray et al. 1998; Rotenberg et al. 2016) and investigated the extent to which landcover, temperature and precipitation correlate with spring vector abundance and BYDV occurrence.

\section{MATERIALS AND METHODS}

Aphid sampling and identification. Aphids were collected from 85 wheat fields across Kansas in the spring of 2014 (12 May to 9 June) and 255 wheat fields in 2015 (18 April to 7 June). All fields sampled were winter wheat and no insecticide seed treatments were applied to sampled fields. GPS coordinates were recorded at each site with a hand-held Garmin device (Supplementary Fig. S1). At the time of sampling, wheat plants were in the physiological stages 8 to 11 on the Feekes growth scale (Large 1954) and did not show obvious disease symptoms. Fields were randomly chosen across Kansas, with a minimum distance between fields of $8 \mathrm{~km}$. Aphids were collected using canvas sweep nets and the number of sweeps per field was standardized to 250 and 100 in 2014 and 2015, respectively. Sweep net samples were taken from a nonstandard transect of each field. Aphids were transferred from nets to plastic 0.38 -liter Ziploc bags and kept in a cooler on ice until processing, when those from each sample site were identified to species and counted. All aphids recovered in each field in each year were identified to species. A subset of live aphids (at most 20/species) were then randomly selected per site, flash frozen in liquid nitrogen and stored at $-80^{\circ} \mathrm{C}$ for further BYDV screening.

Screening aphids for Barley Yellow Dwarf Virus (BYDV). R. padi individuals collected in 2014 and 2015 were tested for the presence of virus (BYDV). However, only S. avenae collected in 2015 were screened due to low sample sizes in 2014. Additionally, nine $S$. avenae samples were damaged and could not be tested. At sites where 10 or more aphids of a species were collected, we screened 10 randomly chosen individuals for BYDV. For sites with fewer than 10 individuals, we screened all individuals collected (ranging from 1 to 9 aphids). Individual $R$. padi were tested for BYDV, whereas groups of pooled $S$. avenae were tested per site. The pooled groups varied in size depending on how many $S$. avenae were collected at a site, with at most 10 aphids pooled and tested for BYDV. We recorded the total number of individual $R$. padi that tested positive and negative for BYDV at each site. Pooled $S$. avenae samples were recorded as either positive or negative for BYDV.

Total RNA was extracted according to manufacturer protocols using the TRIzol (Ambion) method for $R$. padi and the RNeasy Kit (Qiagen) for $S$. avenae. RNA concentration was measured using a Nanodrop 2000 (Thermo Fisher Scientific Inc., Wilmington, DE) and samples were stored at $-80^{\circ} \mathrm{C}$.

Reverse transcription PCR (RT-PCR) with BYDV-specific primers was used to identify viruliferous $R$. padi. Total RNA ( $1 \mu \mathrm{g} / \mathrm{sample}$ ) was converted to cDNA using the High-Capacity cDNA Reverse Transcription Kit (Applied Biosciences) and a 600to 650-bp fragment of the BYDV coat protein gene was amplified using BYL (GTG AAT GAA TTC AGT AGG CCG T) and BYR (GTT CCG GTG TTG AGG AGT CT) primer set. The generic BYL and BYR primers were designed to target BYDV-PAV variants, but may also detect other BYDV species. RT-PCR was performed using a $20-\mu \mathrm{l}$ reaction volume that consisted of $1 \mu \mathrm{l}$ of cDNA, GoTaq (Promega, Madison, WI) reaction buffer, $10 \mathrm{mM}$ nucleotide mix, $0.25 \mu \mathrm{M} /$ primer and $1.25 \mathrm{U}$ of GoTaq DNA polymerase. The following PCR cycling conditions were used: $95^{\circ} \mathrm{C}$ for $5 \mathrm{~min} ; 5$ cycles of $95^{\circ} \mathrm{C}(30 \mathrm{~s}), 60$ to $65^{\circ} \mathrm{C}\left(30 \mathrm{~s}\right.$, increased $1^{\circ} \mathrm{C} /$ cycle $), 72^{\circ} \mathrm{C}$ (30 s); 30 cycles of $95^{\circ} \mathrm{C}(30 \mathrm{~s}), 55^{\circ} \mathrm{C}(30 \mathrm{~s}), 72^{\circ} \mathrm{C}(30 \mathrm{~s})$, followed by a final extension at $72^{\circ} \mathrm{C}$ for $10 \mathrm{~min}$. Products were visualized on a $1 \%$ agarose gel using GelGreen stain (Biotium, Hayward, CA). BYDV-PAV-infected wheat tissue was used as a positive control. A randomly chosen subset of 20 samples that initially tested negative for BYDV were retested to check for false negatives.

A quantitative reverse transcription PCR (qRT-PCR) based method was developed to screen $S$. avenae for presence of BYDV. The iTaq Universal SYBR Green One-Step Kit was used to amplify a 294-bp fragment of the BYDV coat protein with the following primers developed by (Jarošová and Kundu 2010) for qRT-PCR: forward (5'-GTTGAGTTTAAGTCACACGC-3') and reverse (5' TGTTGAGGAGTCTACCTATTTG- $3^{\prime}$ ). Following manufacturer protocols, each one-step qRT-PCR reaction mix contained 100 to $500 \mathrm{ng}$ of total RNA, SYBR Green Supermix, $0.3 \mu \mathrm{M} /$ primer, and iScript Reverse transcription. Reactions were carried out in $20 \mu \mathrm{l}$ volumes on a Bio-RAD CFX Connect System and each sample was run as two technical replicates. A positive control (BYDV-PAV infected wheat tissue) and no template control were included on each plate. The following cycling conditions were used: reverse transcription at $50^{\circ} \mathrm{C}$ for $10 \mathrm{~min}$, denaturation and polymerase activation at $95^{\circ} \mathrm{C}$ for $10 \mathrm{~s}, 40$ cycles of $95^{\circ} \mathrm{C}(10 \mathrm{~s})$ and $60^{\circ} \mathrm{C}(30 \mathrm{~s})$, followed by a melt curve that incrementally increased $0.5^{\circ} \mathrm{C} /$ cycle from 65 to $95^{\circ} \mathrm{C}$. The qRT-PCR products from a subset of 20 samples that tested positive for BYDV were visualized on a $1 \%$ agarose gel using GelGreen stain. An additional $10 \mathrm{~S}$. avenae samples and $23 R$. padi samples that initially tested negative for BYDV were retested using the qRT-PCR method.

Spatiotemporal models of vector and virus dynamics. We used generalized additive models (GAMs) to capture the spatiotemporal dynamics in the abundance of $R$. padi, S. avenae, $S$. graminum and the probability $R$. padi and $S$. avenae were viruliferous (+BYDV). GAMs are a flexible approach that can incorporate variables such as weather or land cover as covariates (dependent variables), but can also model spatial and temporal autocorrelation generated by complex spatiotemporal processes (e.g., population dynamics) (Hefley et al. 2017a; Wood 2017). A tutorial with $\mathrm{R}$ code implementing the statistical analysis and reproducing Supplementary Figs. S2 and S3 is available in Supplementary Appendix S1.

Similar to generalized linear models, GAMs use a distribution for the response variable (e.g., counts of $R$. padi at a site) that matches the characteristics of the response. We assumed a negative binomial distribution for aphid counts because this response variable is restricted to nonnegative integer values (i.e., $0,1,2, \ldots, \infty)$, there is no reasonable upper bound to assume for the counts, and because we expected small scale spatial aggregation (clustering) of aphids that would result in overdispersion (Pielou 1969; Ch. 8). Similarly, we assumed a binomial distribution for the viruliferous $R$. padi data because a known number of $R$. padi were individually tested for BYDV, thus the probability an aphid is viruliferous is captured by the number of BYDV - positive individuals obtained from a known number of tested individuals. We also modeled the spatiotemporal distribution of the expected number of viruliferous $R$. padi. Although we did not collect data directly on this quantity, we obtained the expected number of viruliferous $R$. padi by multiplying the probability an individual aphid was viruliferous by the expected number of $R$. padi, which were obtained from the output of the GAMs. Due to the pooling methods used to sample BYDV in $S$. avenae, the response variable at a site was recorded as "present" if a pooled sample was positive for BYDV and absent otherwise. Thus, we assumed a Bernoulli distribution (binomial distribution with a one "trial"). However, using the results presented in Vansteelandt et al. (2000), individual-level probabilities of viruliferous $S$. avenae can be obtained. We also modeled the spatiotemporal distribution of the expected number of viruliferous $S$. avenae. We obtained 
the expected number of viruliferous $S$. avenae by multiplying the probability an individual aphid was viruliferous by the expected number of $S$. avenae, which were obtained from the output of the GAMs.

For each site, we used the PRISM Climate database (NCAR 2015) to obtain the monthly temperature and total precipitation for fall (September, October, and November), winter (December, January, and February), and spring (March, April, and May). Seasonal averages were measured for climate variables at each site, which were calculated as the average of the monthly averages within each season. Seasonal temperatures and precipitation varied across years and study sites. For example, seasonal averages for maximum and minimum temperatures and precipitation varied across years. In 2014, average temperatures ranged $\left(T_{\min }-T_{\max }\right)$ from 16 to $19^{\circ} \mathrm{C}$ in fall, -3 to $1^{\circ} \mathrm{C}$ in spring and 3 to $6^{\circ} \mathrm{C}$ in winter. In 2015 , average temperatures ranged from 15 to $20^{\circ} \mathrm{C}$ (fall), -1 to $5^{\circ} \mathrm{C}$ (winter) and 4 to $8^{\circ} \mathrm{C}$ (spring). Total precipitation also varied in fall ( 111 to $522 \mathrm{~mm}$; 196 to $615 \mathrm{~mm}$ ), winter (14 to $84 \mathrm{~mm} ; 9$ to $98 \mathrm{~mm}$ ), and spring (27 to $284 \mathrm{~mm} ; 42$ to $400 \mathrm{~mm}$ ); for 2014 and 2015, respectively. Fall and winter were the seasons prior to spring aphid collection (e.g., fall 2014 precipitation was used for data collected in spring 2015). For each site, we obtained two land cover covariates (distance to nearest grass/pasture and distance to nearest forest/shrub) from the 30 by $30 \mathrm{~m}$ resolution 2011 National Land Cover Database (NLCD). We used the NLCD land class numbers and defined grass/pasture as the amalgamation of land classes 71 and 81 and forest/shrub as the amalgamation of land classes 41 and 52.

To account for the heterogeneous sampling effort (i.e., 250 and 100 sweeps per field in 2014 and 2015, respectively), we included an offset term, which is similar to including a covariate of effort (e.g., number of sweeps). An offset term is fixed and, in our study, assumed that an effort of 250 sweeps would, on average, result in a counts 2.5 times larger than the count obtained from 100 sweeps. As such, our results are reported or displayed as the expected number of aphids per 100 sweeps.

To capture the spatiotemporal effect that was not explained by changes in sampling effort, weather, or land cover covariates (i.e., autocorrelation; Table 1 in Hefley et al. 2017a), we included a categorical variable of the year of data collection (except for BYDV presence in S. avenae which we only had data for 2015) and used thin plate regression splines to capture spatial autocorrelation. Briefly, thin plate regression splines are a type of basis function that can be used to model the "smooth" effects of spatial location or time (Hefley et al. 2017a). The GAM framework allows for linear effects of covariates such as weather or land cover as well as nonlinear effects that are captured by basis functions (e.g., spatial location). As such, we included a nonlinear effect of spatial location and both the weather and land cover covariates as linear effects in the GAM.

After fitting the GAM to each data set we conducted several model checking procedures and present relevant results in what follows. Determining which variables influence the spatiotemporal distribution of a species or disease can be a challenge for two reasons. The first challenge is that the variables of interest (e.g., weather and land cover) are often correlated, which results in a wellknown problem in regression-type models known as collinearity (Dormann et al. 2013). Collinear covariates have the potential to make regression coefficient estimates highly variable (i.e., have a large variance) and may also result in models where inference is sensitive to small changes in model specification (e.g., the inclusions or exclusions of a single variable may influence the inference for other variables in a model). In our study, the pairwise correlation between all land cover (grass/pasture, forest/shrub) and weather covariates (fall, winter, and spring precipitation and mean monthly temperature) produced coefficients of determination $\left(R^{2}\right)$ that ranged from 0.15 to 0.67 . For some weather covariates the correlations were sufficiently high to challenge our ability to reliably determine which variables are driving the spatiotemporal distribution of the three vectors and the probability of BYVD infection. The second challenge is similar to collinearity, but relates to correlation between covariates that are location or time specific (e.g., precipitation and temperature, land cover) and basis vectors used to account for autocorrelation (Hodges and Reich 2010; Wood 2017). As noted in Hefley et al. (2017a; p. 644), collinearity among covariates and basis vectors is a current topic of research in spatial statistics and is a difficult problem to address in applied problems, with no clear remedy (Hanks et al. 2015; Hefley et al. 2016, 2017a, b; Hodges and Reich 2010).

TABLE 1. Summary of vector abundance and presence of viruliferous (+BYDV [Barley yellow dwarf virus]) aphids across the nine agricultural districts of Kansas ${ }^{\mathrm{a}}$

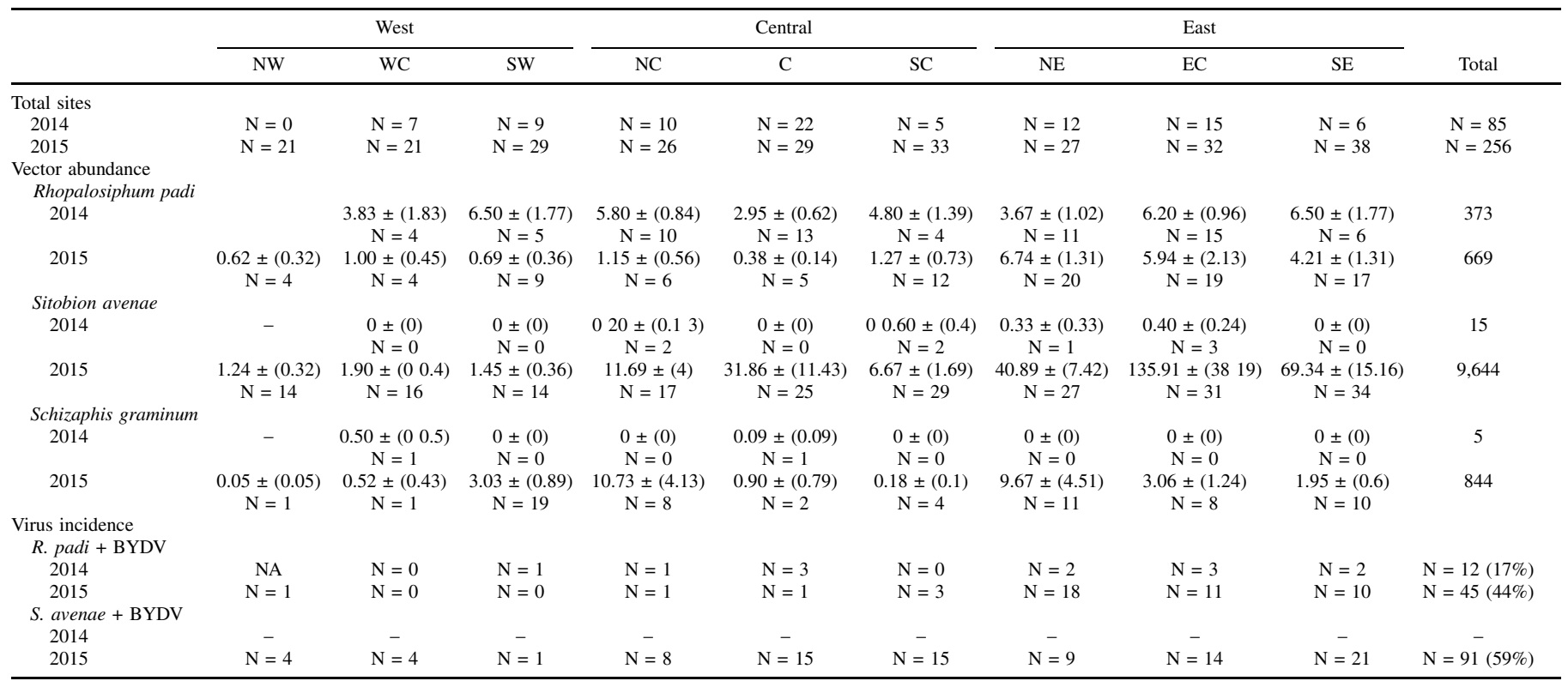

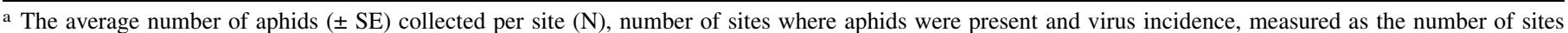
where +BYDV viruliferous aphids were detected. Total number of each aphid species and total number of sites (\%) where viruliferous aphids were detected are also shown. 
Given the challenges with identifying the drivers of the spatiotemporal distribution of a vector species or disease, we report for each vector or BYDV incidence analysis the coefficient estimates for covariates having $90 \%$ confidence intervals (CIs) that did not contain zero. However, the "statistical significance" of these results should be interpreted with caution (Hefley et al. 2016, 2017a, b; Hodges and Reich 2010). Although the statistical inference related to which drivers influence the spatiotemporal distribution may be challenging to determine in our study, it is important to note that predictions obtained from the model are typically accurate and not influenced by the collinearly among covariates or among basis vectors (Hanks et al. 2015; Hefley et al. 2017b).

\section{RESULTS}

Distribution and abundance of vectors and virus. Drastic shifts occurred in the abundance and distribution of vector species during the study (Table 1, Fig. 1). Similar numbers of $R$. padi were collected per site in eastern counties both years, but in 2015 fewer individuals were collected in central and western counties (Table 1, Fig. 1). S. avenae abundance was higher in 2014 than 2015 , with overall greater numbers of individuals collected per site across all agricultural districts in 2015. Average numbers of $S$. graminum collected per site were generally low $(<1$ individual), with a few pockets of greater abundance observed in the north central and north eastern portions of Kansas in 2015 (Table 1, Fig. 1). Overall, in 2014, R. padi was the predominant vector species present in $81 \%$ of fields sampled, whereas $S$. avenae and $S$. graminum were present in only 9 and $2 \%$ of fields, respectively. In contrast, S. avenae was present in $81 \%$ of field samples in 2015 , compared with $R$. padi $(40 \%)$ and $S$. graminum $(27 \%)$. The abundance of $R$. padi varied little between collection sites in 2014, but in 2015, both $R$. padi and $S$. avenae densities were greater in eastern than western Kansas (Table 1; Fig. 1).
A 2014
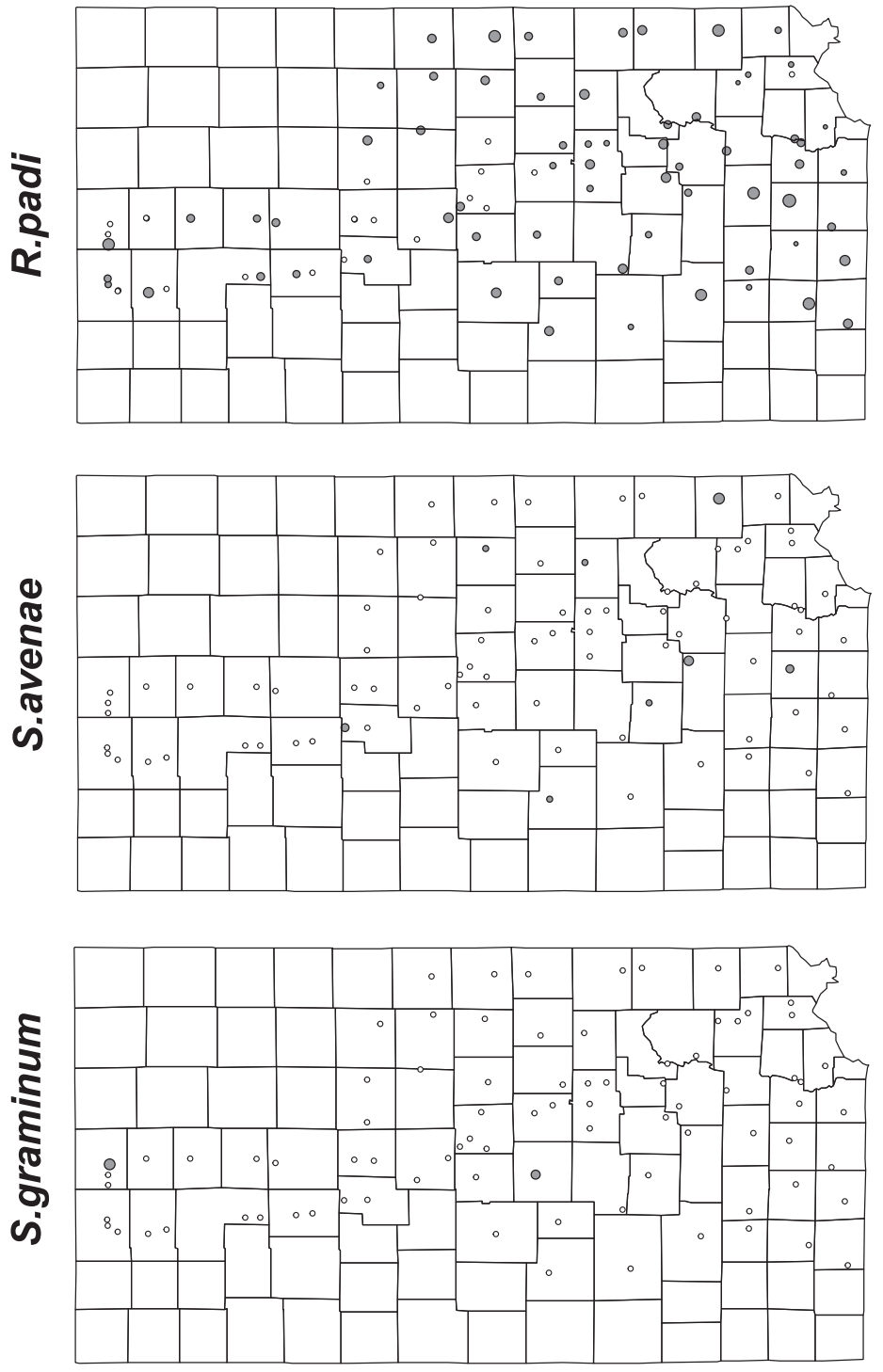

B 2015
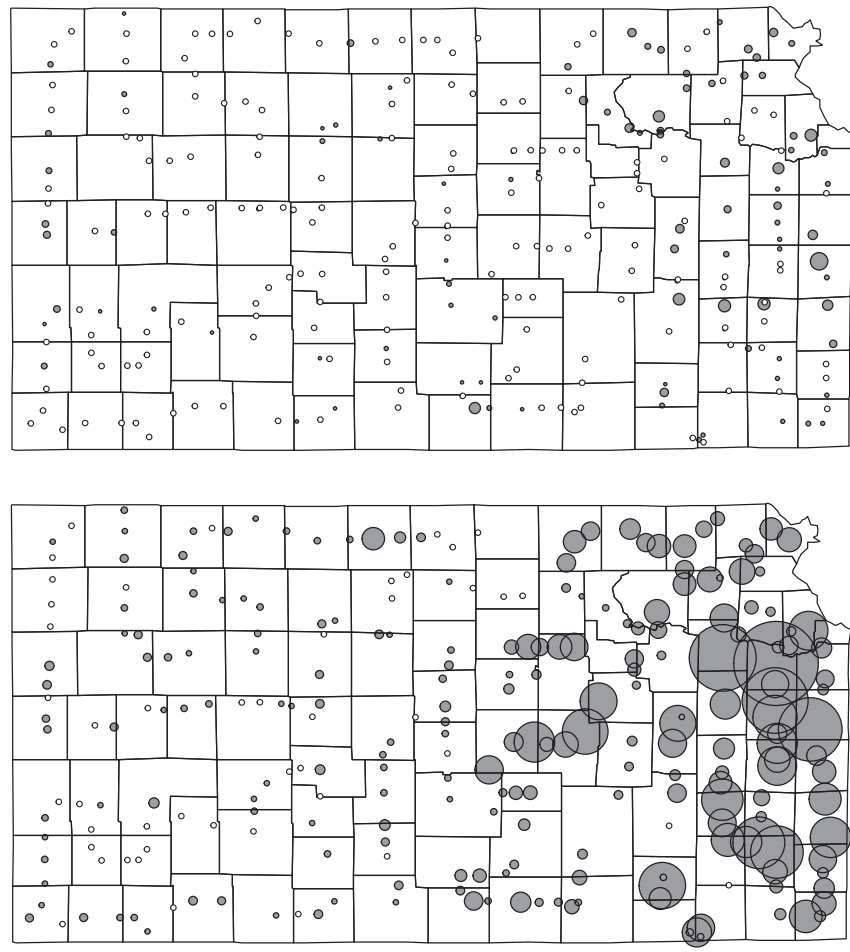

Number of aphids 10 100 1000

Fig. 1. Distribution and abundance of aphids collected from Kansas wheat fields in A, 2014 and $\mathbf{B}, 2015$. The diameter of each circle is scaled to the total numbers of aphids collected at each site for a given vector species. 
The incidence of BYDV positive R. padi from 2014 to 2015 mirrored the distribution and abundance of this vector, with occurrence of viruliferous aphids increasing from $17 \%$ of sites in 2014, to $44 \%$ in 2015, and a greater BYDV incidence in eastern than western counties in both years (Fig. 2). Viruliferous (+BYDV) S. avenae were collected in $59 \%$ of fields in 2015, but unlike $R$. padi the distribution was more uniform across the state (Fig. 2B).

Environmental variables associated with vector and virus occurrence. The expected numbers of $R$. padi, S. avenae, and S. graminum showed distinct spatiotemporal patterns in 2015 (Fig. 3) and in 2014. The expected number of all three vectors was highest in the eastern half of the study area, but small regions of relatively high abundance of $R$. padi and S. graminum occurred in the western portions of Kansas (Fig. 3A and C).

For $R$. padi, coefficients for land cover covariates (distance to grass/pasture and forest/shrub) and average monthly temperature and total precipitation in fall, winter or spring had $90 \%$ CIs that included zero, indicating that these variables may not significantly influence the spatiotemporal distribution of this vector.

For $S$. avenae, the mean fall and spring temperature and total spring precipitation were the only weather or land cover covariates with coefficients that had $90 \%$ CIs that did not contain zero. Mean fall temperature had a positive coefficient estimate, indicating that increases in mean fall temperature may have increased the expected number of $S$. avenae during the sampling period. Conversely, mean spring temperature and spring precipitation had coefficient estimates that were negative, indicating that increases in these covariates may have reduced the expected number of $S$. avenae during the sampling period.

For $S$. graminum, total fall precipitation, and mean winter temperature were the only weather or land cover covariates with a $90 \% \mathrm{CI}$ that did not include zero. Both covariates had negative coefficient estimates, indicating that increases in these covariates may have reduced the expected number of $S$. graminum during the sampling period.

The probability an individual $R$. padi was viruliferous had a distinct spatiotemporal pattern (Fig. 4A). Fall and winter precipitation were the only weather or land cover covariates with a 90\% CI that did not include zero. The coefficient estimate for fall precipitation was positive, indicating that higher precipitation in the fall may have increased the probability of viruliferous $R$. padi during the following spring sampling period. Conversely, the coefficient estimate for winter precipitation was negative, indicating that increased winter precipitation may have decreased the probability of viruliferous $R$. padi. We obtained the expected number of viruliferous $R$. padi in 2015 (Fig. 4B) by multiplying the probability of viruliferous $R$. padi (Fig. 4A) by the expected number of $R$. padi (Fig. 3A). Similarly, the expected number of viruliferous $R$. padi in 2014 was obtained by multiplying the probability of viruliferous $R$. padi by the expected number of $R$. padi. As a result, the derived expected number of viruliferous $R$. padi also showed strong spatiotemporal patterns in both years.

The probability an individual $S$. avenae was viruliferous also had a distinct spatiotemporal pattern (Fig. 4C). Mean fall temperature and distance to nearest forest/shrub were the only weather or land cover covariates with a $90 \% \mathrm{CI}$ that did not include zero. The coefficient estimate for mean monthly fall temperature was positive, indicating that higher temperatures in the fall may have increased the presence of viruliferous $S$. avenae at a site during the following spring sampling period. The coefficient estimate for land cover associated with forest/shrubland was also positive, indicating that as the distance away from forested areas or those dominated by shrubs increases, the probability an individual $S$. avenae is viruliferous increases as well. We obtained the expected number of viruliferous $S$. avenae in 2015 (Fig. 4D) by multiplying the probability an individual $S$. avenae was

\section{A 2014}

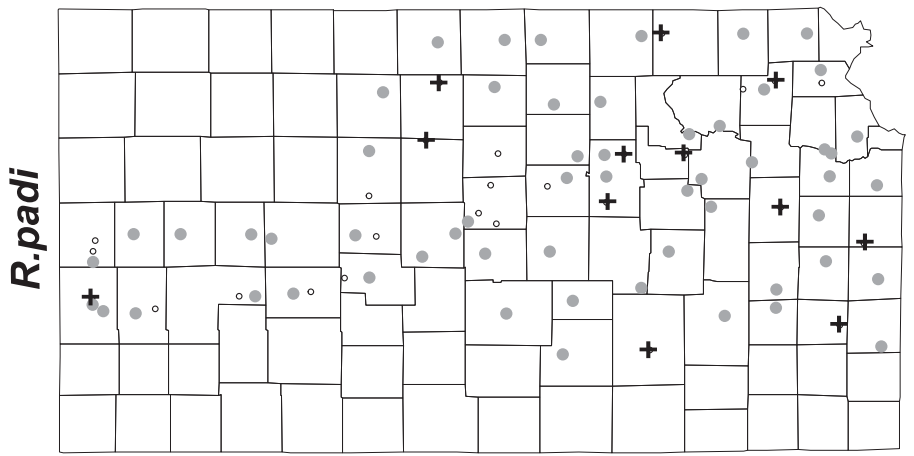

\section{B 2015}
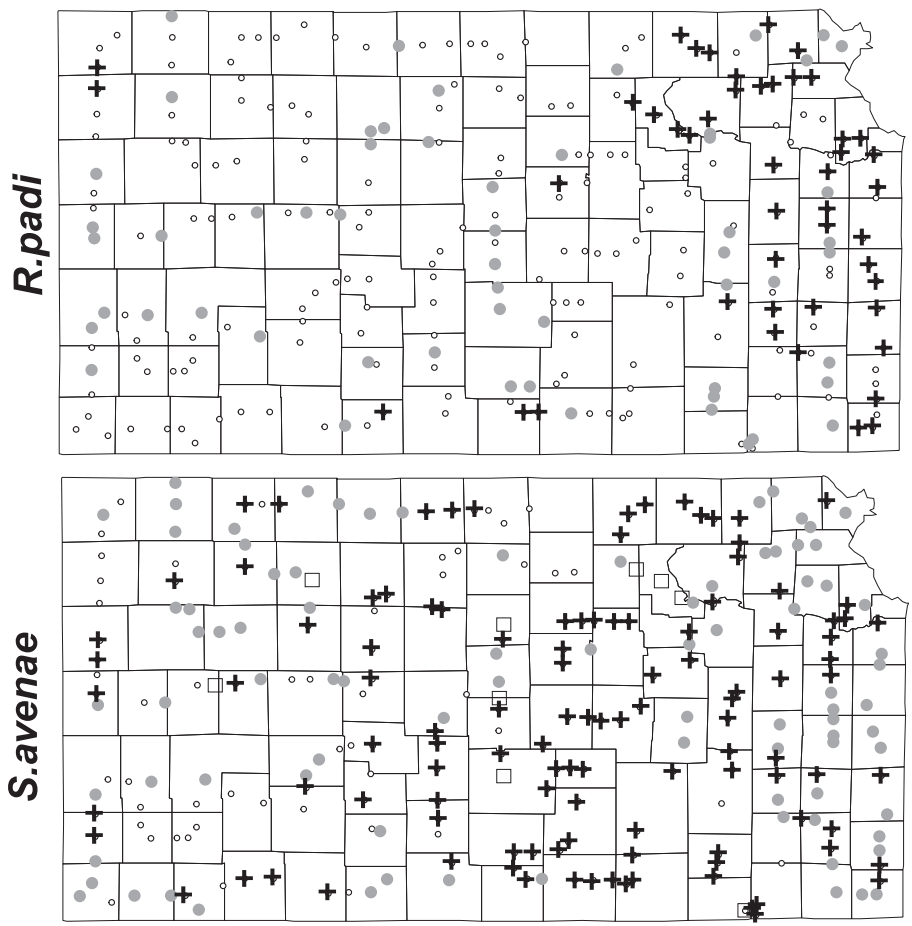

+ Viruliferous aphids present - Viruliferous aphids absent - No aphids present

\section{$\square$ Aphids not tested}

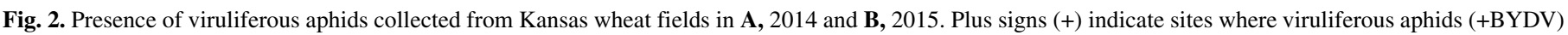

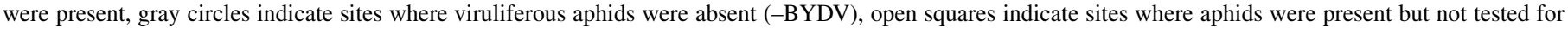
virus, and open circles indicate sites where no aphid vectors were collected. 
viruliferous (Fig. 4C) by the expected number of $S$. avenae (Fig. 3B). Finally, it should be noted that Figure 4 show maps of the expected or "potential" proportion of viruliferous aphids assuming a given point was wheat.

\section{DISCUSSION}

Forecasting future epidemics of barley yellow dwarf disease in cereal agroecosystems is challenging due to the complexity of virus-vector-plant interactions and the potential for environmental conditions to shape pathosystem dynamics. Barley yellow dwarf has historically caused major yield reductions in the U.S. Great Plains, accounting for average annual losses of $33 \%$ from 2005 to 2013 in Kansas alone (Gaunce and Bockus 2015). Considerable effort has been made to identify environmental conditions that impact BYDV spread and damage in cereal crops, primarily via effects on vector migration and establishment of fall populations (Fabre et al. 2003, 2005; Hesler et al. 2005; Kendall and Chinn 1990). However, we currently lack a complete understanding of how climate and land use contribute to maintaining the BYDV pathosystem in North America. Determining what environmental conditions are favorable for perpetuating the spread of vectors and virus will enable better predictions of infection risk and aide in identifying potential breaking points in the cycle for improved disease management.

Our study is the first to investigate the effects of climatic and land cover variables on the abundance of spring vector populations and the prevalence of viruliferous vectors of BYDV (R. padi and $S$. avenae) in the Great Plains. Spring vector populations play an important role in increasing overall disease incidence by providing late-season inoculum for infecting cultivated and perennial grasses that serve as local over-summering hosts, thus sustaining the cycle of BYD in cereal agroecosystems. Overall, we found substantial
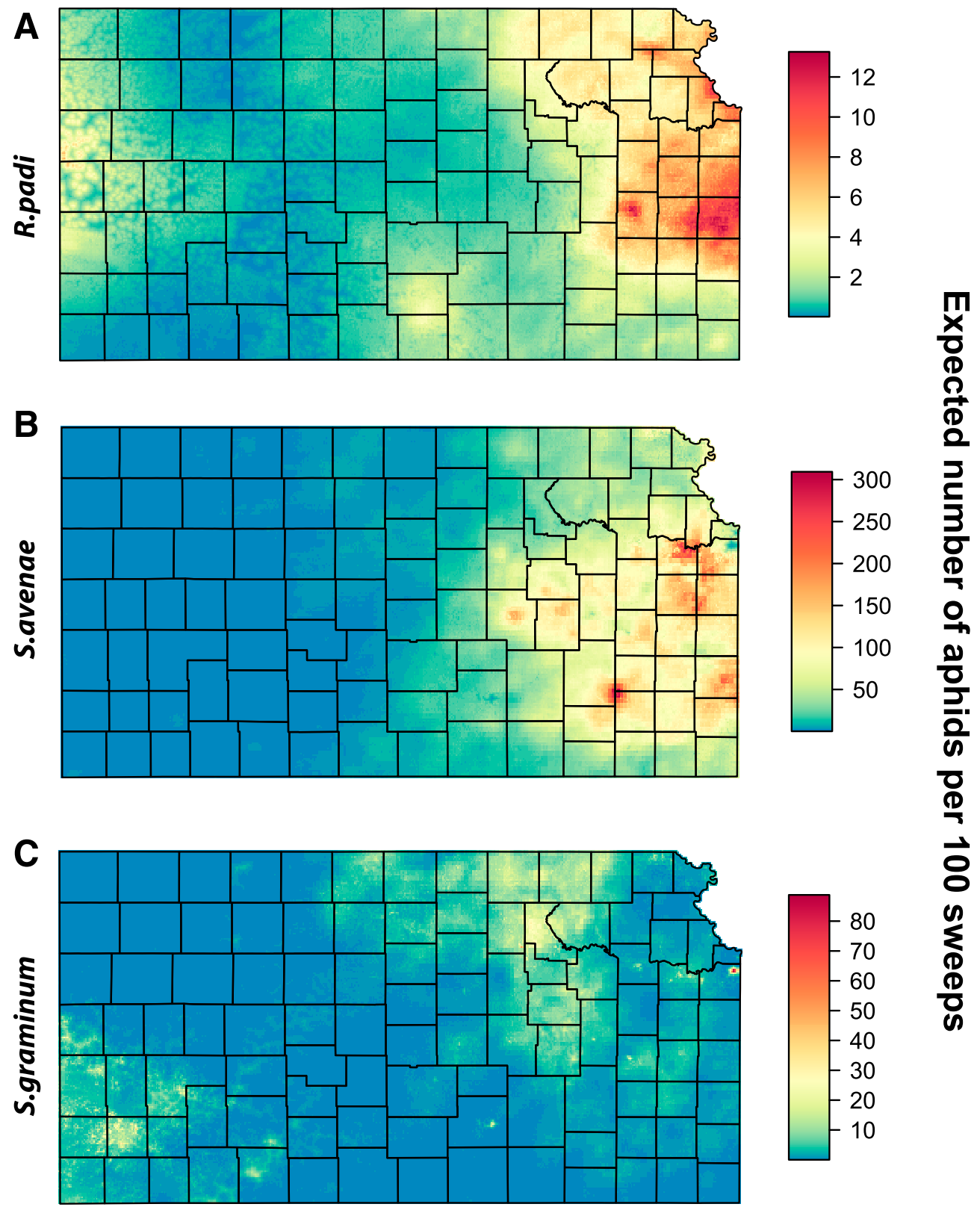

Fig. 3. Expected number of aphids per 100 sweeps of three vectors of Barley yellow dwarf virus (BYDV). Panels show A, Rhopalosiphum padi, B, Sitobion avenae, and $\mathbf{C}$, S. graminum. Each map shows the spatial distribution of expected abundance resulting from spatiotemporal variables varying on a 3-month interval (e.g., seasonal mean temperature) and assuming the land cover is wheat. Maps do not take into account the specific agricultural landscape and can be interpreted as the "potential" number of aphids expected if a given point on the map was wheat. The maps shown are spatial predictions for 2015. 
shifts in aphid abundance between years (Figs. 1 and 2) and distinct spatiotemporal patterns of vector species and BYDV incidence (Figs. 3 and 4). Average fall temperatures and precipitation were positively associated with abundance of and probability that viruliferous $S$. avenae and $R$. padi were present, while several additional winter and spring covariates showed negative associations with their presence (Fig. 5). In general, associations between land cover variables and differences in abundance or probability that viruliferous individuals were present in spring vector populations were not "statistically significant".

Our results support previous work suggesting fall conditions are important drivers of BYD dynamics in cereal agroecosystems (Fabre et al. 2006; Harrington et al. 1999). The proportion of viruliferous $R$. padi collected in autumn months has previously been shown to be predictive of disease severity and yield losses (Fabre et al. 2003; Kendall and Chinn 1990; Quillec et al. 1995). Environmental conditions that support greater fall infestation levels on winter cereals may also lead to increased local overwintering success and ultimately higher spring vector abundance. In the current study, spatiotemporal modeling revealed fall temperature was positively associated with spring abundance and probability an individual $S$. avenae was viruliferous (Fig. 5). Various aspects of aphid vector biology depend upon temperature, such as population growth rate, migration, and virus transmission (Dixon 1977; Lowles et al. 1996; Power et al. 2011). Temperature is also widely recognized as playing a critical role in the establishment and overwintering success of aphid populations in cultivated and uncultivated grasses (Fabre et al. 2006; Thackray et al. 2009). In addition, fall precipitation was positively associated with the probability of viruliferous individuals in spring populations of $R$. padi (Fig. 5). Fall precipitation could benefit vector populations by promoting the growth of additional grass hosts that provide a "green bridge" for vector survival between growing seasons (Thackray et al. 2009). Favorable seasonal conditions, such as warmer average temperatures and increased rainfall, may therefore generally contribute to the stability of the BYDV pathosystem by facilitating the establishment and growth of aphid populations in both the fall and spring.

Interestingly, we found several weather covariates were negatively associated with vector abundance and presence of viruliferous aphids. Specifically, increased winter precipitation was associated with lower probability of viruliferous $R$. padi in populations and higher average spring temperature and precipitation were associated with lower spring $S$. avenae abundance. Prolonged or heavy snow cover could increase overwintering mortality and possibly delay spring flights from perennial grasses to winter cereals. In contrast, milder winters have been predicted to increase overwintering success and allow for earlier establishment in cereals, subsequently leading to higher spring vector abundance (Fabre et al. 2003; Pons et al. 1993; Quillec et al. 1995). Sheppard et al. (2015) recently demonstrated that spring emergence of $R$. padi and $S$. avenae across Britain is correlated with winter climate on longer time scales ( $>4$ years), supporting the hypothesis that winter temperatures drive first flight synchrony and aphid abundance in spring. Finally, warmer spring temperatures may result in vector population sizes peaking earlier, while heavier spring rains can increase mortality by washing aphids from plants, which could generally contribute to lower spring $S$. avenae counts.

Identifying environmental variables that influence BYDV incidence has important implications for management practices and forecasting the effects of climate change on BYDV epidemiology in the Great Plains (Michaud 2010; Walls et al. 2016). Several models have been developed to predict BYD epidemics in Australia and Europe (Jones et al. 2010) and establish guidelines for making management decisions related to vector control (Walls et al. 2016). Our results indicate that the inclusion of specific climatic variables could allow fine tuning of predictive management models for growers to assess the risk of infection on a local scale. Specifically, results from our spatiotemporal models suggest fall weather conditions could be used for long-range forecasting of the future abundance and BYDV incidence of spring aphid populations. Information regarding abundance and infectivity rates of spring vector populations should be incorporated into models to improve recommendations for optimal management strategies (e.g., planting dates, insecticide application). Finally, climatic warming is expected to positively affect cereal aphid migration, fecundity, overwintering success, and virus transmission efficiency in the Great Plains (Michaud 2010). Warmer winters will likely increase the occurrence of year-round parthenogenetic vector populations in the northern hemisphere, as has been documented in Europe (Ruszkowska 2005), and could
A

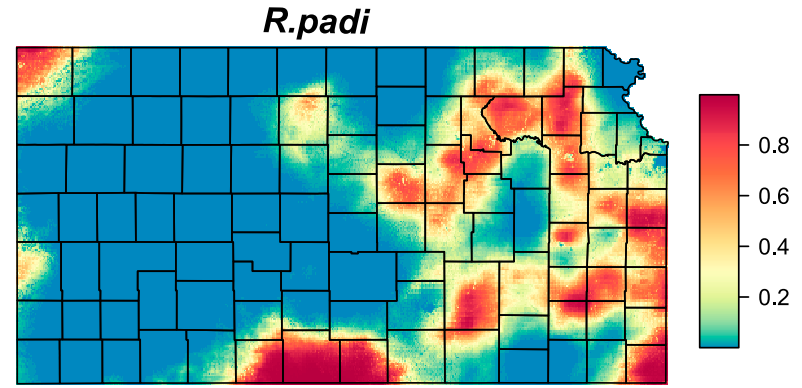

B

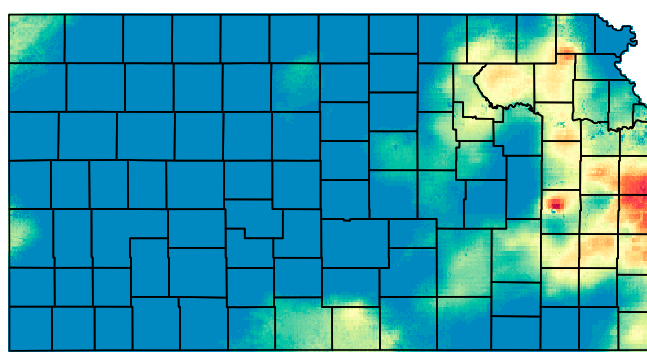

C

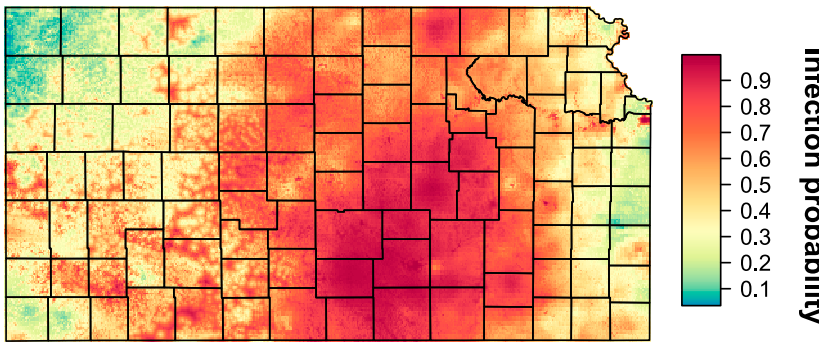

Fig. 4. A, The probability of viruliferous Rhopalosiphum padi, B, the expected number of viruliferous $R$. padi per 100 sweeps, C, probability of viruliferous

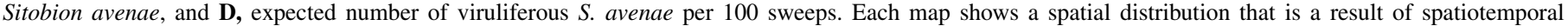

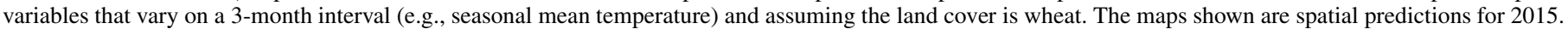


permit long-distance migration and spread of BYDV to more northern regions.

In general, we found $R$. padi and $S$. avenae were more prevalent at Eastern sample sites where ground cover consists more of pasture and grassland than cropland, suggesting perennial grasses provide over-summering sites and pose risks as potential reservoirs for BYDV. Interestingly, recent work detected no such regional differences in BYDV infection of Kansas wheat fields, although sampling efforts were primarily focused on central and Western growing regions (Rotenberg et al. 2016). Summer cereals (e.g., corn and barley) and native perennial grasses have been proposed as possible "green bridges" that sustain vector populations through late spring and summer months, when winter cereal hosts are unavailable (Brown et al. 1984; Clement et al. 1986). However, it remains unclear whether over-summering hosts of cereal aphids contribute to maintaining the BYDV pathosystem in the Great Plains by providing virus reservoirs for new fall infections in winter cereals. Extensive surveys of western U.S. grasslands have identified a number of perennial species that serve as hosts to BYDV (Ingwell and Bosque-Pérez 2015; Power et al. 2011), while relatively little is known about infection rates in uncultivated grass communities of the Great Plains (Malmstrom et al. 2011). A survey of the Konza Prairie Tallgrass Preserve in Kansas found BYDV present in three of four dominant tallgrass prairie species, but BYDV-PAV was not among the isolates detected (Garrett et al. 2004). Instead, infection rates of BYDV-MAV (S. avenae vectored) and BYDV-SGV ( $S$. graminum vectored) isolates were as high as $60 \%$. Seasonal surveys in Indiana also found fescue grasses infected by multiple BYDV isolates, while Kentucky bluegrass was only found to be infected by BYDV-RMV (Clement et al. 1986). Further research is needed to determine whether viruliferous spring vector populations contribute to creating virus reservoirs in perennial grasses that could ultimately translate to higher infectivity of fall migrants. Such data are needed to increase the accuracy of predicting BYDV transmission rates.

Although proximity to uncultivated grasses and summer cereals is thought to be critical to maintain the BYD cycle, very little is known about how landscape characteristics influence the BYDV pathosystem. Two studies have investigated the extent to which patterns of regional land use associated with winter cereals, spring cereals, meadows and fodder crops explain variation in vector abundance and BYDV infection rates (Coceano et al. 2009; Fabre et al. 2005). Fabre et al. (2005) reported a positive correlation between the ratio of area sown with winter cereals relative to maize and percent of viruliferous $R$. padi collected in the fall. Aphid suction trap data collected in Italy over 20 years showed hectare age devoted to pasture grasses was positively associated with fall $R$. padi migrant numbers, while $S$. graminum catches in spring and summer increased with acreage of spring-sown cereals (Coceano et al. 2009). In contrast, vector abundance and probability of viruliferous individuals showed no distinct patterns associated with distance to nearest grass/pasture in the current study. However, there was a positive association with distance to nearest forest/ shrubland and the probability an individual $S$. avenae tested positive for BYDV (Fig. 5). However, we did not investigate the extent to which patterns of land use associated with planting of summer cereals (e.g., maize, sorghum) predict spring aphid abundance and BYDV incidence. Further research is needed to determine whether agricultural land use or land cover could be used to predict vector and virus dynamics.

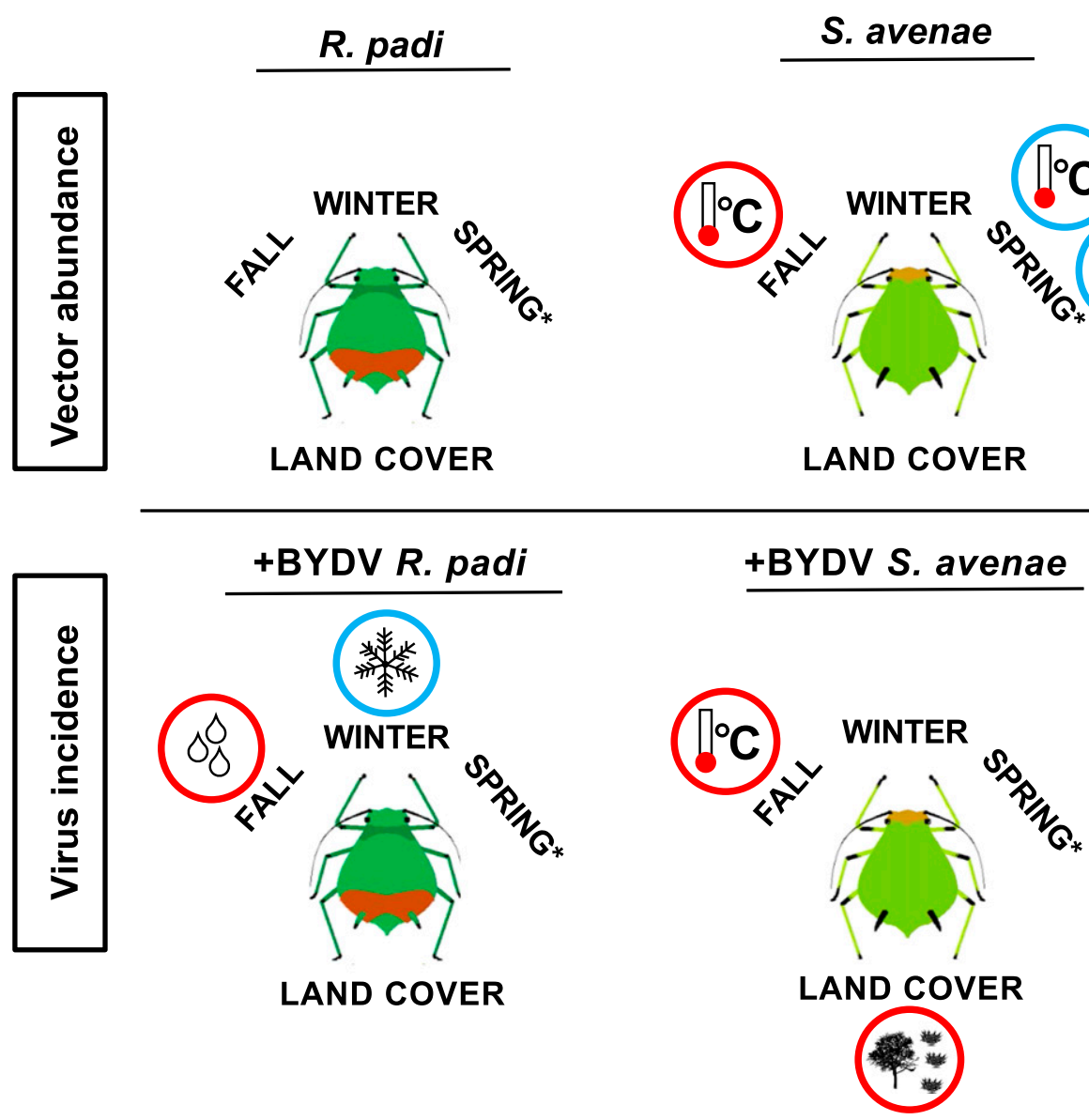

Fig. 5. Summary of results from generalized additive models (GAMs) used for capturing spatiotemporal dynamics of spring vector abundance and Barley yellow dwarf virus (BYDV) incidence. The linear effects of weather and land cover variables prior to aphid collection (fall, winter) and during the spring collection period (SPRING*) were included. Red circles around a covariate indicate a positive association and blue circles indicate a negative association. 


\section{ACKNOWLEDGMENTS}

This is contribution number 19-033-J from the Kansas Agricultural Experiment Station.

\section{LITERATURE CITED}

Ali, M., Hameed, S., and Tahir, M. 2014. Luteovirus: Insights into pathogenicity. Arch. Virol. 159:2853-2860.

Blackmer, J. L., and Bishop, G. W. 1991. Population dynamics of Rhopalosiphum padi (Homoptera: Aphididae) in corn in relation to barley yellow dwarf epidemiology in southwestern Idaho. Environ. Entomol. 20:166173.

Bragard, C., Caciagli, P., Lemaire, O., Lopez-Moya, J. J., MacFarlane, S., Peters, D., Susi, P., and Torrance, L. 2013. Status and prospects of plant virus control through interference with vector transmission. Annu. Rev. Phytopathol. 51:177-201.

Brault, V., Uzest, M., Monsion, B., Jacquot, E., and Blanc, S. 2010. Aphids as transport devices for plant viruses. C. R. Biol. 333:524-538.

Brown, J. K., Wyatt, S. D., and Hazelwood, D. 1984. Irrigated corn as a source of barley yellow dwarf virus and vector in eastern Washington. Phytopathology 74:46-49.

Burnett, P. A. 1991. Breeding for resistance to barley yellow dwarf. Misc. Publ.-Agric. Exp. Stn. Oklahoma State University.

Burrows, M., Franc, G., Rush, C., Blunt, T., Ito, D., Kinzer, K., Olson, J., O'Mara, J., Price, J., Tande, C., and Ziems, A. 2009. Occurrence of viruses in wheat in the Great Plains region, 2008. Plant Health Progress.

Chapin, J. W., Thomas, J. S., Gray, S. M., Smith, D. M., and Halbert, S. E. 2001. Seasonal abundance of aphids (Homoptera: Aphididae) in wheat and their role as barley yellow dwarf virus vectors in the South Carolina coastal plain. J. Econ. Entomol. 94:410-421.

Clement, D. L., Lister, R. M., and Foster, J. E. 1986. ELISA-based studies on the ecology and epidemiology of barley yellow dwarf virus in Indiana. Phytopathology 76:86-92.

Coceano, P. G., Peressini, S., Bianchi, G. L., and Caciagli, P. 2009. Long-term changes of aphid vectors of Barley yellow dwarf viruses in north-eastern Italy (Friuli-Venezia Giulia). Ann. Appl. Biol. 155:37-50.

D'Arcy, C. J., and Burnett, P. A. 1995. Barley Yellow Dwarf: 40 Years Of Progress. American Phytopathological Society, St. Paul, MN.

Dixon, A. F. 1977. Aphid ecology: Life cycles, polymorphism, and population regulation. Annu. Rev. Ecol. Syst. 8:329-353.

Dormann, C. F., Elith, J., Bacher, S., Buchmann, C., Carl, G., Carré, G., Marquéz, J. R. G., Gruber, B., Lafourcade, B., Leitão, P. J., and Münkemüller, T. 2013. Collinearity: A review of methods to deal with it and a simulation study evaluating their performance. Ecography 36:27-46.

Fabre, F., Dedryver, C.-A., Leterrier, J. L., and Plantegenest, M. 2003. Aphid abundance on cereals in autumn predicts yield losses caused by Barley yellow dwarf virus. Phytopathology 93:1217-1222.

Fabre, F., Pierre, J. S., Dedryver, C.-A., and Plantegenest, M. 2006. Barley yellow dwarf disease risk assessment based on Bayesian modelling of aphid population dynamics. Ecol. Modell. 193:457-466.

Fabre, F., Plantegenest, M., Mieuzet, L., Dedryver, C. A., Leterrier, J.-L., and Jacquot, E. 2005. Effects of climate and land use on the occurrence of viruliferous aphids and the epidemiology of barley yellow dwarf disease. Agric. Ecosyst. Environ. 106:49-55.

Garrett, K. A., Dendy, S. P., Power, A. G., Blaisdell, G. K., Alexander, H. M., and McCarron, J. K. 2004. Barley yellow dwarf disease in natural populations of dominant tallgrass prairie species in Kansas. Plant Dis. 88:574.

Gaunce, G. M., and Bockus, W. W. 2015. Estimating yield losses due to barley yellow dwarf on winter wheat in Kansas using disease phenotypic data. Plant Health Prog. 16:1.

Gray, S., and Gildow, F. E. 2003. Luteovirus-aphid interactions. Annu. Rev. Phytopathol. 41:539-566.

Gray, S. M., Chapin, J. W., Smith, D. M., Banerjee, N., and Thomas, J. S. 1998. Barley yellow dwarf luteoviruses and their predominant aphid vectors in winter wheat grown in South Carolina. Plant Dis. 82:1328-1333.

Habekuss, A., Riedel, C., Schliephake, E., and Ordon, F. 2009. Breeding for resistance to insect-transmitted viruses in barley-An emerging challenge due to global warming. J. Fur Kult. 61:53-61.

Hanks, E. M., Schliep, E. M., Hooten, M. B., and Hoeting, J. A. 2015. Restricted spatial regression in practice: Geostatistical models, confounding, and robustness under model misspecification. Environmetrics 26:243254.

Harrington, R., Mann, J., Burgess, A., Tones, S., Rogers, R., Blake, S., Morrison, S., Ward, L., Barker, I., Morgan, D., and Walters, K. F. A. 1999. Development and validation of decision support methodology for control of barley yellow dwarf virus. HGCA Proj. Rep. 205.
Hefley, T. J., Broms, K. M., Brost, B. M., Buderman, F. E., Kay, S. L., Scharf, H. R., Tipton, J. R., Williams, P. J., and Hooten, M. B. 2017a. The basis function approach for modeling autocorrelation in ecological data. Ecology 98:632-646.

Hefley, T. J., Hooten, M. B., Drake, J. M., Russell, R. E., and Walsh, D. P. 2016. When can the cause of a population decline be determined? Ecol. Lett. 19:1353-1362.

Hefley, T. J., Hooten, M. B., Russell, R. E., Walsh, D. P., and Powell, J. A. 2017b. When mechanism matters: Bayesian forecasting using models of ecological diffusion. Ecol. Lett. 20:640-650.

Hesler, L. S., Riedell, W. E., Langham, M. A., and Osborne, S. L. 2005. Insect infestations, incidence of viral plant diseases, and yield of winter wheat in relation to planting date in the northern Great Plains. J. Econ. Entomol. 98:2020-2027.

Hodges, J. S., and Reich, B. J. 2010. Adding spatially-correlated errors can mess up the fixed effect you love. Am. Stat. 64:325-334.

Ingwell, L. L., and Bosque-Pérez, N. A. 2015. New experimental hosts of Barley yellow dwarf virus among wild grasses, with implications for grassland habitats. Plant Pathol. 64:1300-1307.

Jarošová, J., Chrpová, J., Šíp, V., and Kundu, J. K. 2013. A comparative study of the Barley yellow dwarf virus species PAV and PAS: Distribution, accumulation and host resistance. Plant Pathol. 62:436-443.

Jarošová, J., and Kundu, J. K. 2010. Validation of reference genes as internal control for studying viral infections in cereals by quantitative real-time RTPCR. BMC Plant Biol. 10:146.

Jones, R. A., Salam, M. U., Maling, T. J., Diggle, A. J., and Thackray, D. J. 2010. Principles of predicting plant virus disease epidemics. Annu. Rev. Phytopathol. 48:179-203.

Kendall, D. A., and Chinn, N. E. 1990. A comparison of vector population indices for forecasting barley yellow dwarf virus in autumn sown cereal crops. Ann. Appl. Biol. 116:87-102.

Large, E. C. 1954. Growth stages in cereals illustration of the Feekes scale. Plant Pathol. 3:128-129.

Lowles, A. J., Tatchell, G. M., Harrington, R., and Clark, S. J. 1996. The effect of temperature and inoculation access period on the transmission of barley yellow dwarf virus by Rhopalosiphum padi (L.) and Sitobion avenae (F.). Ann. Appl. Biol. 128:45-53.

Lucio-Zavaleta, E., Smith, D. M., and Gray, S. M. 2001. Variation in transmission efficiency among Barley yellow dwarf virus-RMV isolates and clones of the normally inefficient aphid vector, Rhopalosiphum padi. Phytopathology 91:792-796.

Malmstrom, C. M., Melcher, U., and Bosque-Pérez, N. A. 2011. The expanding field of plant virus ecology: Historical foundations, knowledge gaps, and research directions. Virus Res. 159:84-94.

Michaud, J. P. 2010. Implications of climate change for cereal aphids on the Great Plains of North America. Pages 69-89 in: Aphid Biodiversity Under Environmental Change. Springer, Dordrecht.

Miller, W. A., and Rasochová, L. 1997. Barley yellow dwarf viruses. Annu. Rev. Phytopathol. 35:167-190.

Nault, L. R. 1997. Arthropod transmission of plant viruses: A new synthesis. Ann. Entomol. Soc. Am. 90:521-541.

NCAR. 2015. The Climate Data Guide: PRISM high-resolution spatial climate data for the United States: Max/min temp, dewpoint, precipitation. National Center for Atmospheric Research (NCAR). https://climatedataguide.ucar. edu/climate-data/prism-high-resolution-spatial-climate-data-united-statesmaxmin-temp-dewpoint

Ng, J. C., and Perry, K. L. 2004. Transmission of plant viruses by aphid vectors. Mol. Plant Pathol. 5:505-511.

Papura, D., Jacquot, E., Dedryver, C. A., Luche, S., Riault, G., Bossis, M., and Rabilloud, T. 2002. Two-dimensional electrophoresis of proteins discriminates aphid clones of Sitobion avenae differing in BYDV-PAV transmission. Arch. Virol. 147:1881-1898.

Parry, H. R., Macfadyen, S., and Kriticos, D. J. 2012. The geographical distribution of yellow dwarf viruses and their aphid vectors in Australian grasslands and wheat. Australas. Plant Pathol. 41:375-387.

Pielou, E. C. 1969. An Introduction to Mathematical Ecology. John Wiley \& Sons, New York.

Pons, X., Comas, J., and Albajes, R. 1993. Overwintering of cereal aphids (Homoptera: Aphididae) on durum wheat in a Mediterranean climate. Environ. Entomol. 22:381-387.

Power, A. G., Borer, E. T., Hosseini, P., Mitchell, C. E., and Seabloom, E. W. 2011. The community ecology of barley/cereal yellow dwarf viruses in Western US grasslands. Virus Res. 159:95-100.

Quillec, F. L.-L., Tanguy, S., and Dedryver, C. A. 1995. Aerial flow of barley yellow dwarf viruses and of their vectors in western France. Ann. Appl. Biol. 126:75-90.

Roossinck, M. J. 2015. Plants, viruses and the environment: Ecology and mutualism. Virology 479:271-277. 
Rotenberg, D., Bockus, W. W., Whitfield, A. E., Hervey, K., Baker, K. D., Ou, Z., Laney, A. G., De Wolf, E. D., and Appel, J. A. 2016. Occurrence of viruses and associated grain yields of paired symptomatic and nonsymptomatic tillers in Kansas winter wheat fields. Phytopathology 106: 202-210.

Ruszkowska, M. 2005. Protecting winter cereals against aphids, virus vectors. Ochrona Roslin 50:24-26.

Shah, S. J. A., Bashir, M., and Manzoor, N. 2012. A Review on Barley yellow dwarf virus. Pages 747-782 in: Crop Production Agriculture Improvement. Springer, Dordrecht.

Sheppard, L. W., J. R.Bell, R.Harrington, and D. C.Reuman. 2015. Changes in large-scale climate alter spatial synchrony of aphid pests. Nature Climate Change 6:610-613.

Thackray, D. J., Diggle, A. J., and Jones, R. A. C. 2009. BYDV PREDICTOR: A simulation model to predict aphid arrival, epidemics of Barley yellow dwarf virus and yield losses in wheat crops in a Mediterranean-type environment. Plant Pathol. 58:186-202.

Thies, C., Roschewitz, I., and Tscharntke, T. 2005. The landscape context of cereal aphid-parasitoid interactions. Proc. R. Soc. Lond. B Biol. Sci. 272: 203-210.

Vansteelandt, S., Goetghebeur, E., and Verstraeten, T. 2000. Regression models for disease prevalence with diagnostic tests on pools of serum samples. Biometrics 56:1126-1133.

Walls, J. T., Caciagli, P., Tooker, J. F., Russo, J. M., Rajotte, E. G., and Rosa, C. 2016. Modeling the decision process for barley yellow dwarf management. Comput. Electron. Agric. 127:775-786.

Whitfield, A. E., Falk, B. W., and Rotenberg, D. 2015. Insect vector-mediated transmission of plant viruses. Virology 479:278-289.

Wood, S. 2017. Generalized Additive Models: An Introduction with R. CRC Press, Boca Rotan, FL. 